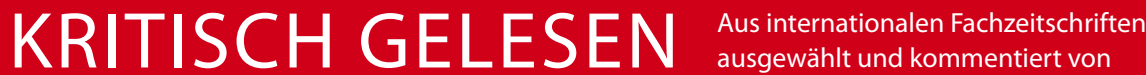

Prof. Dr. med.
$\begin{aligned} & \text { H. S. FüeßI } \\ & \text { Isar-Amper- } \\ & \text { Klinikum, } \\ & \text { KI. München-Ost, } \\ & \text { Haar }\end{aligned}$

\section{Ärzteehen halten länger!}

\section{Die Ehe- und Lebenspartner von Ärzten und Ärztinnen sind mit der Beziehung trotz einiger berufs- spezifischer Erschwernisse in der Regel sehr zufrieden.}

— In den USA wurden 891 Partner von Ärzten und Ärztinnen aller Fachrichtungen zu ihrer Partnerschaft befragt. Mit der Partnerschaft waren $87 \%$ zufrieden, $55 \%$ sogar extrem zufrieden. Etwa die Hälfte verbrachte mindestens $90 \mathrm{Mi}$ nuten täglich mit ihrem Partner, jeweils ein Viertel nur 45-90 oder weniger als 45 Minuten. Mit ihren Erfahrungen würden $80 \%$ erneut die Ehe mit einem/r

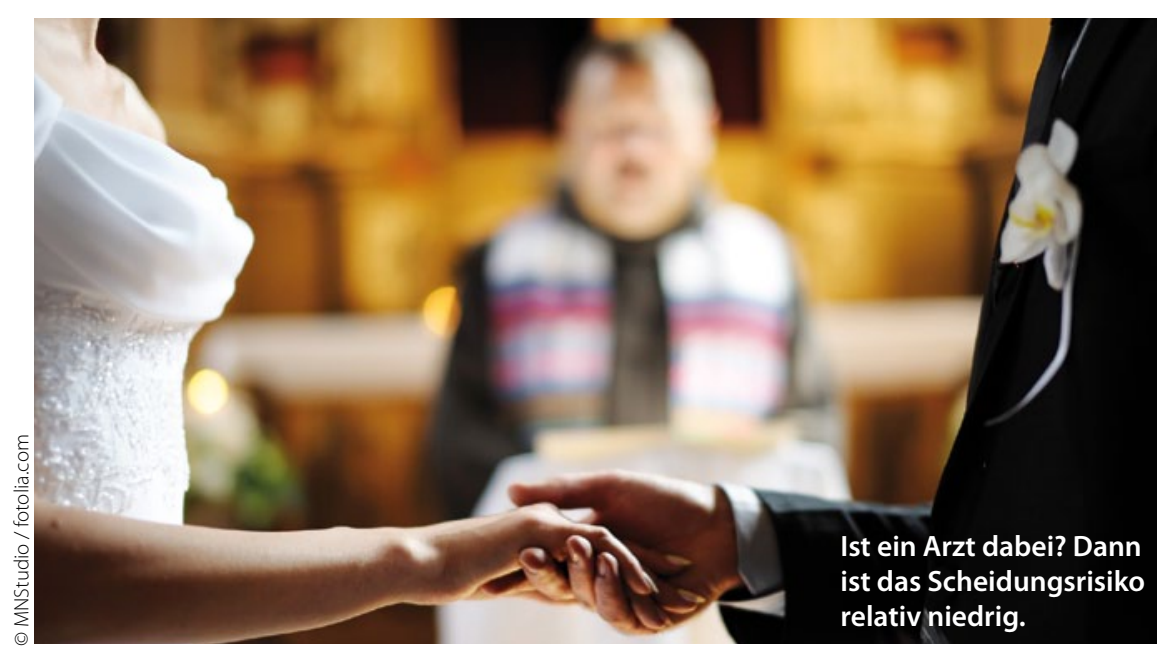

Arzt/Ärztin eingehen. Nur 12\% hatten im abgelaufenen Jahr ernsthaft eine Trennung erwogen.

Die Partner sind also überwiegend zufrieden mit der Beziehung, obwohl der Arzt an einigen Tagen der Woche zu müde für gemeinsame Unternehmungen nach Hause kommt (44\%), häufig nervös (34\%) und noch mit seinen Gedanken bei der Arbeit ist (46\%). Die Zufriedenheit der Beziehung korreliert positiv mit der Dauer der gemeinsam verbrachten Stunden, negativ mit der Dauer der Arbeitszeit und der Häufigkeit der Rufbereitschaft des Arztes.
- T. D. Shanafelt et al.

The medical marriage: a national survey of the spouses/partners of US physicians. Mayo Clin. Prod. 2013; 88: 216-225

\section{Kommentar}

Die Zufriedenheit in Ehen mit Ärzten ist bislang meist aus der Sicht des Arztes untersucht worden. Hier wird nun die Sichtweise des Partners analysiert. Einige Klischees sind korrekturbedürftig: Mit dem demografischen Wandel sind heute 25\% der Arztpartner Männer, die Mehrzahl der Ärzte arbeitet ganztägig außerhalb des Hauses, und sehr viele Arztpartner sind mit der Beziehung zufrieden oder sogar extrem zufrieden. Das ist bemerkenswert, denn US-Ärzte arbeiten nach Erhebungen aus dem Jahr 2012 wöchentlich zehn Stunden länger als andere Berufsgruppen, erleiden häufiger ein Burnout und sind unzufrieden mit der Relation von Arbeit zu Freizeit. Ob ein guter sozialer Status einige Nachteile des Arztberufes kompensiert, bleibt unklar. Jedenfalls liegen die Scheidungsraten bei Ehen mit Ärzten (kumulativ 29\% in Verlauf von 30 Jahren) in den USA niedriger als bei Ehen mit anderen Berufsgruppen.

H. HOLZGREVE = 